\title{
METHODOLOGY OF EXPERIMENTAL RESEARCH OF COLD-FORMED STEEL MEMBERS
}

\author{
Tatiana Nazmeeva \\ Saint-Petersburg State Polytechnical University, Saint-Petersburg, Russia
}

E-mail:naztv@mail.ru

\begin{abstract}
Now erection volume of pre-fabricated energy-efficient buildings and constructions based on the technology of frame house building using light steel thin-walled structures is steadily rising, which gives us an opportunity of economical use of limited fuel-and-power resources. C-shaped profile and C-shaped notched profile are used as frame members. The author of the article has been carrying out a research on light steel thin-walled structures. The author of the article developed methodology of testing and designed two testing beds C-12 (1200mm/20t) and B-50 (2200mm/50t) to carry out experimental investigations. Numerical solution of stability of a thin-walled member made of C-shaped profile was developed during the numerical simulation done in PLM Femap 10.1 Nastran.
\end{abstract}

Keywords: cold-formed profile, testing bed, local buckling, methodology, strain-gauge, thin-walled members, numerical simulation.

\section{Introduction}

Reliable performance of any building construction is impossible without understanding its original behavior under workload as well as without it in the stages of manufacture, storage, transportation and installation. Understanding of an original behavior of a structure or a material is impossible when only theoretical methods are used. An experiment is the basis for studying any structure behavior.

As a matter of fact, the main aim of doing experimental analysis is to find out actual behavior of a building structure and the material it is made of. The main task of such testing is to set up a correspondence between the real behavior of a building structure and its design diagram.

Light steel thin-walled structures are the structures based on cold-formed galvanized steel sections with the thickness up to $3 \mathrm{~mm}$. The section may have open or closed sections of different shape (C-shaped, Z-shaped etc.), and load-carrying capacity of elements made of cold-formed thin-walled sections is influenced by their design features.

The technology of frame house building using light steel thin-walled structures originates from the USA and Canada. Nowadays it is also widely used in Europe. Low weight of the load-bearing steel framework (between $20-25 \mathrm{~kg} / \mathrm{m} 2$ ), short payback period and high energy efficiency of the buildings made of light steel thin-walled structures are the factors which make them to be in great demand for housing as well as for construction of industrial and public building (Vatin, Popova 2006) (Ghersi et al.2002). Due to their design features light steel thin-walled structures are able to solve the main problems of building reconstruction: to decrease foundation and walls loads, to carry out construction works in the restrained urban conditions without use of heavy equipment and without shutdown of the process inside the building. Light steel thin-walled structures are used in passive housing.

Nowadays there is steadily rising demand for light steel thin-walled structures (Zhmarin 2012). But the shortage of relevant normative documents on light steel thin-walled structures design and use that contain the guidelines taking into account Russian conditions leads to the current situation, when light steel thin-walled structures are used according to the recommended guidelines of thin-walled structure producers. So, load bearing capacity of light steel thin-walled structures is used partly and this leads to unduly high construction costs of buildings made of light steel thin-walled structures and, hence, limits wide use of these effective structures.

Now we have a well-developed theory of behavior of steel thin-walled members. Works by Vlasov V.Z. (Vlasov 1959), Timoshenko S.P. (Rybakov 2010) and other scientists are widely known. Nowadays, the research on steel thin-walled members takes up a problem of application study of behavior of different types of light steel thin-walled building structures (trusses, frameworks, beams, etc.) (Yurchenko 2010, Smaznov 2009). The main aim of the research is to develop reliable engineering theories of their calculation and designing. Nowadays, mainly numerical investigations of the behavior of thinwalled members are conducted (Tusnin 2009). It is very difficult to carry out such research only with the help of numerical investigations in view of different circumstances (clamped boundary conditions, defects, etc.). It is necessary to carry out tests in situ.

European Design Code (ENV 1993-1-3:2001), created according to the results of wide scale research, reveals different characteristics of cold-formed steel member behavior. In AISI the Direct Strength Method by Schafer B.W is of use. In the Russian national standards there is no clear systematization of thin-walled member calculations. So, to develop our own standards we have to carry out a large number of investigations and organize the data obtained. By now such tests of structures based on thin-walled members have been carried out in some university laboratories of our country (Astakhov 2006).

In particular, theoretical and experimental investigations on global lateral-torsional buckling and capacity of coldformed steel members of C-shaped sections of different cross-sections under pressure are studied. C-shaped profile and C-shaped notched profile (Fig. 1) are used for 
framework members. Many specialists consider this shape to be the most rational when different deformations take place, because it has greater stability and durability in comparison with other profile types.

Notches on the webs of $\mathrm{C}$-shaped notched profile are made with a fly knife when the profile is made of a blank. In this case a portion of steel is not removed from the section, as it happens when we use punching, that is why this profile should be called 'notched', not perforated. Lengthwise notches made chequerwise in the profile walls increase the distance of heat flow and consequently decrease heat conductivity and eliminate cold bridges.

Notches made in the profile webs surely influence the bearing capacity and stability of the structures where the profiles are used. But in spite of its extensive use in frame construction, the behavior of compressed members made of notched profile is not enough studied.

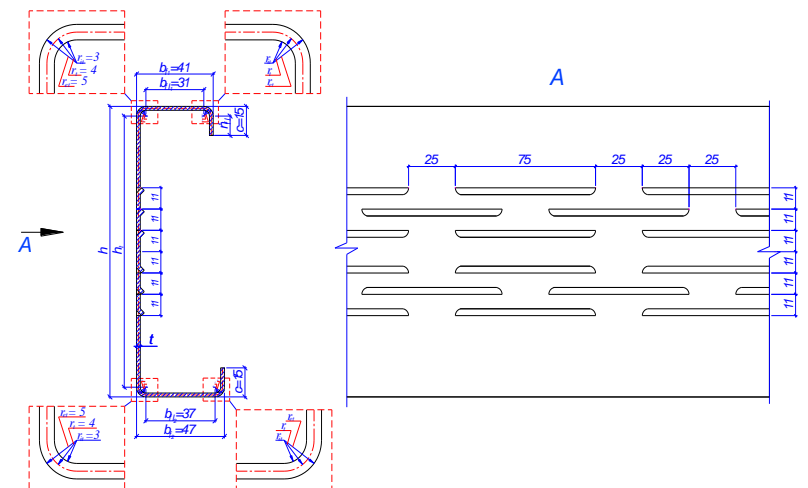

Fig. 1. Cold-formed steel notched C-shaped profile

So, studying of the behavior of compressed members made of notched C-shaped profile is very important for their reliable use in building.

\section{Theoretical investigations and design approach}

This article includes the results we received during our study of single members of $2.2 \mathrm{~m}$ height made of notched (TC) and solid (ПC) cold-formed C-shaped profile (Fig. 2), gimbaled in the guiding rail with the help of selftapping screws (Fig.3). Characteristics of cross-section: height $h-150$ and $200 \mathrm{~mm}$, thickness $-2,0 \mathrm{~mm}$.

We took 4 series (TC-150-2,0, ПC-150-2,0, TC-200-2,0, ПС-200-2,0) of dominant tests in each of which we tested 5 members of each cross-section type. Total number of members tested is 20 .

The members are made of steel 08 GOST 14918-80 with yield strength not less than $23 \mathrm{kN} / \mathrm{cm}^{2}$.

Theoretical estimation of the cross-section revealed that the profile flange does not show any cross-section reduction, and the web works depending on the effective width.

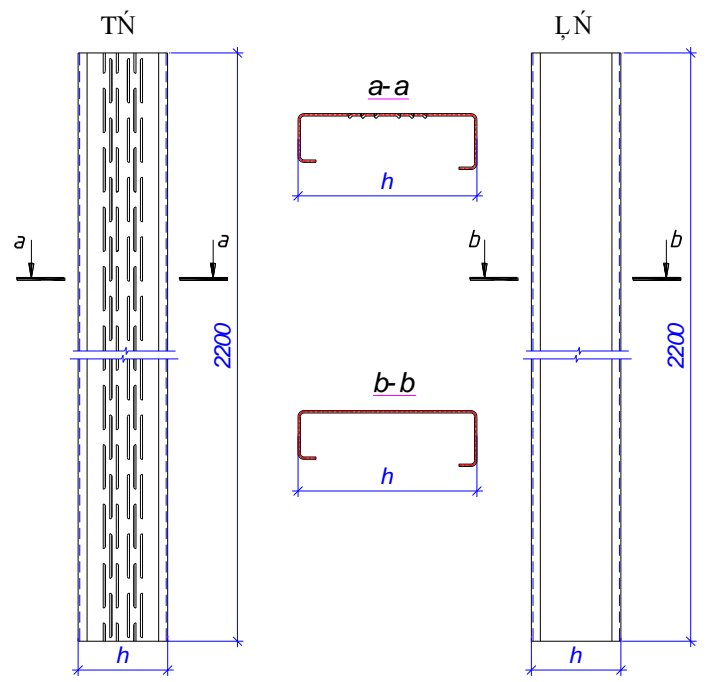

Fig. 2. Member tests.

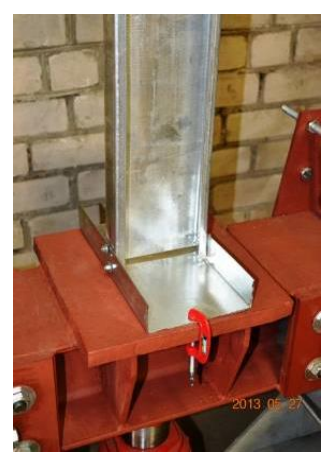

Fig. 3. Cold-formed C-shaped profile, gimbaled in the guiding rail with the help of self-tapping screws.

Theoretical estimation of buckling and bearing capacity of test members showed:

- global buckling will be flexural-torsional;

- critical force of global lateral-torsional buckling was $N_{\text {cr,et }}=24.2 \mathrm{kN}$; corresponding bearing capacity according to Eurocode (ENV 1993-1-3:2001) is $N_{\text {b Rd }}=82.25 \mathrm{kN}$;

- bearing capacity exhaustion of the members will not be associated with the local flexural buckling but with global lateral-torsional buckling;

- distortional buckling will occur earlier than the global lateral-torsional buckling because the lips are not large.

The author of the article has developed two test facilities C-12 (1200 mm/20 t) and B-50 (2200 mm/50 t) (Fig. 4) for carrying out the experimental work. Testbench equipment is made with due regard to the specific character of thin-walled members real-life environment behaviour, necessary fixing of patterns are explored and scheme of load application are used.

Nowadays, there is no methodology of carrying out experimental work on thin-walled structures in Russia that is why we had to develop our own methodology. It was developed taking into account the European Design Code. 


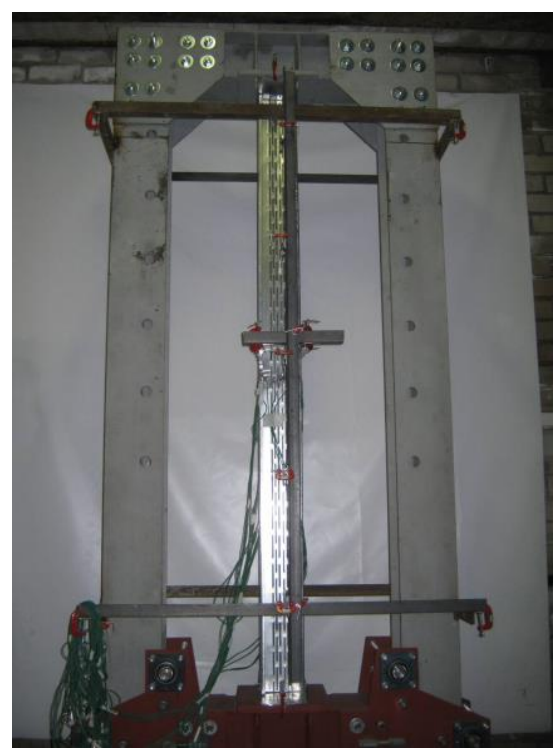

Fig. 4. Testing bed B-50 $(2200 \mathrm{~mm} / 50 \mathrm{t})$.

Sometimes it is difficult to estimate the stableness of elements working with little models, because it is rather difficult to simulate in it those features of a full-scale structure which greatly influence the critical force magnitude. Stableness is usually explored until the pattern is crashed to study post-critical behavior and determine baring capacity reserve under changes of stress and strain state of the system (Brune, Ungermann 2008). When studying real behavior of a building structure, it is desirable to carry out research with the help of special testing facilities or testing beds. During the tests objects are under the loads, which are equal or higher than those in actual conditions. The main advantage of carrying out tests on the testing bed is the possibility to estimate the object's response to specific conditions (load limits, definite type and load value), all other things constant. This helps to find out latent defects or reserve of structure bearing capacity (Wallace, James A. et al. 2001). Testing bed is a rigid frame, which the model is bearing on.

It is difficult to carry out compression tests of long thin-walled elements using usual compression apparatus because it cannot provide gradual loading and height enough for the patterns under the test. The developed testing complex (Fig. 5) is a testing bed (frame), subsystem of the testing object loading and control equipment instrumentation to fix the object's response to the loading.

The character of changes of external loads acting on building structures greatly impacts the development of methods and means of structure tests. Load can be applied from top or be mounted at the bottom. It is helpful to measure loads with strain meters placed into power circuits or pressure sensors, the principles of work of which are also based on tensity resistive effect. In this case continuous recording of loads can be performed. When investigation is not limited by elastic work of a material, automated recording of loading-deformation data should be carried out, all the data should be taken and load registered in the shortest time.

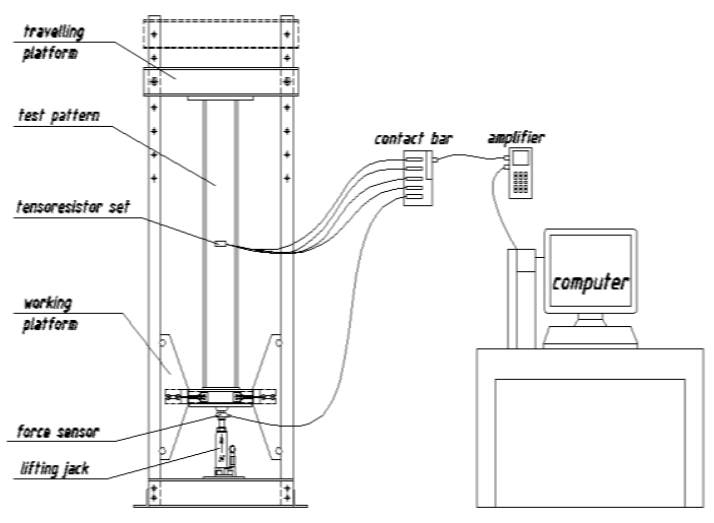

Fig. 5. Testing complex.

Because of specific nature of member work, during this experiment load was applied from the bottom with cuddies and its magnitude was controlled with a cylinder strain meter. As a rule, loads are applied a little at a time and measurements of deformations and displacements are taken after each step of loading using strain-gauge measurement. A maximum possible number of sensors are put on the flanges and wall of the profile (Fig. 6).

In this research strain-gauges and measuring control equipment made according to the technical documentation of «Tokyo Sokki Kenkyujo Co., Ltd.» were used. These resistive-strain sensors have bases $1-120 \mathrm{~mm}$, their working temperature range is $-20 \mathrm{C}-+80 \mathrm{C}$. The sensors can be installed on metal, concrete, glass, etc. They are developed for research and are good for studying postcritical behavior of galvanized steel sections.

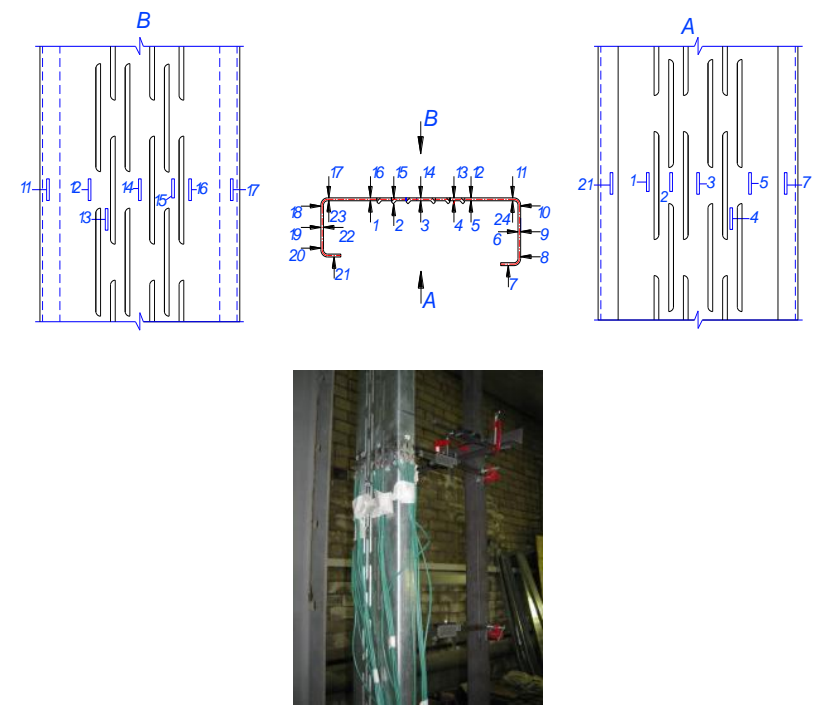

Fig. 6. The scheme of strain-gauge installation along the crosssection of notched $\mathrm{C}$-shaped profile.

It is a digital electric-measuring multi-purpose instrument, its operating principle is based on conversion of input signal from sensing element (resistive-strain sensors) into digital form with the help of ADC and its further processing and displaying the results of measurements. So, ADC in this device is built in and a researcher reads a ready result without using any auxiliary devices, that is why it is portable. This device is used in complex with contact bars to which wires from sensors are connected. 
The author of the article has all necessary certificates for work with the sensors and measuring equipment mentioned.

Table 4. Test evaluation of long thin-walled members (2.2 m).

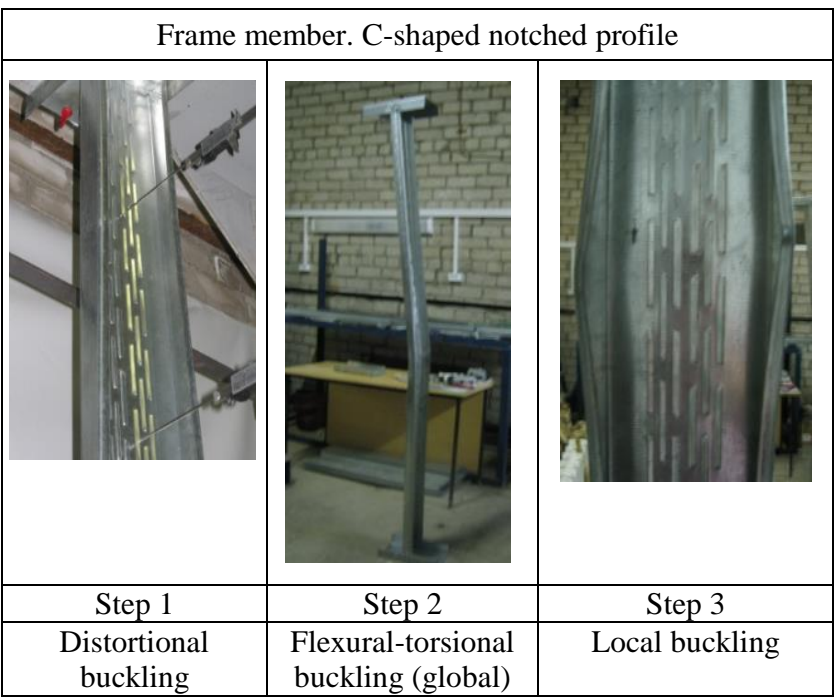

Research by itself includes a set of trial tests and a set of dominant tests. The set of trial tests is carried out before the dominant tests to adjust the work of the testing bed, to check the measuring equipment, strain-gauges, and to check the way of structure fixing and the ways loads can be applied, which were chosen according to the numerical simulation results. The trial tests over, corrections and dominant tests are carried out. Research is carried out according to the order to fulfill the aims and tasks of the experiment and with due regard to safety, which is observed in the experiment layout.

To avoid errors connected with the material relaxation, instrument readings are taken immediately. During the experiment comfort temperature should be kept in the room to enable the measuring equipment work properly. After carrying out the research, processing of measurement results is performed taking into account nonlinear material behaviour.

During our testing we measured web crippling deformations for every member (Fig. 7). Cross-sectional deformations of 3 members with cross-sectional height of $150 \mathrm{~mm}$ were measured, the curves of membrane stresses were made (Fig. 8) and comparison study of elastic curves for the members was performed (Fig. 9).

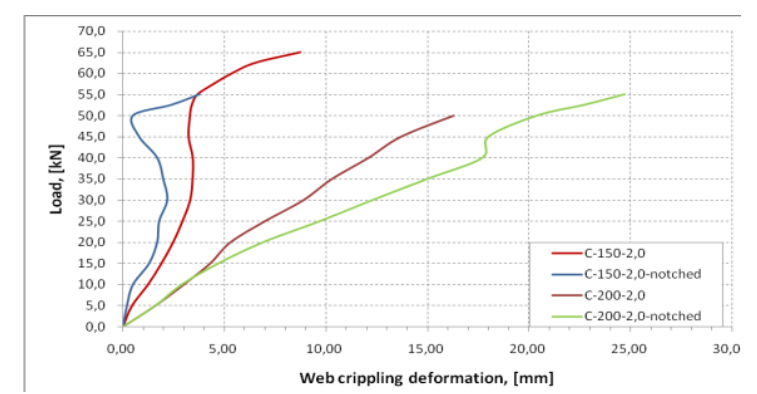

Fig. 7. Load-deformation curves for long members-tests $(2.2 \mathrm{~m})$ with thickness $=2.0 \mathrm{~mm}$.
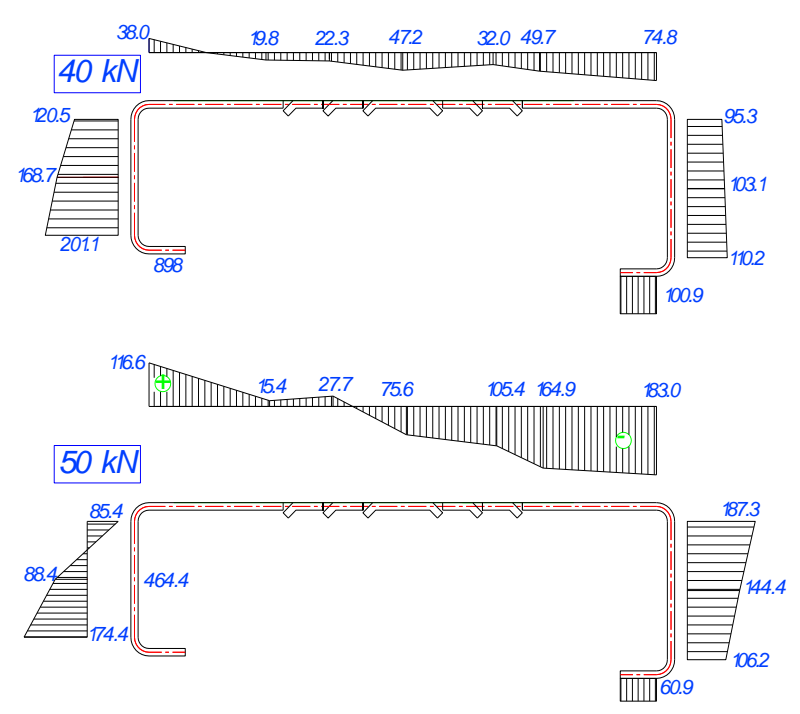

Fig. 8. Member TC-150-2,0. Membrane stresses, MPa.
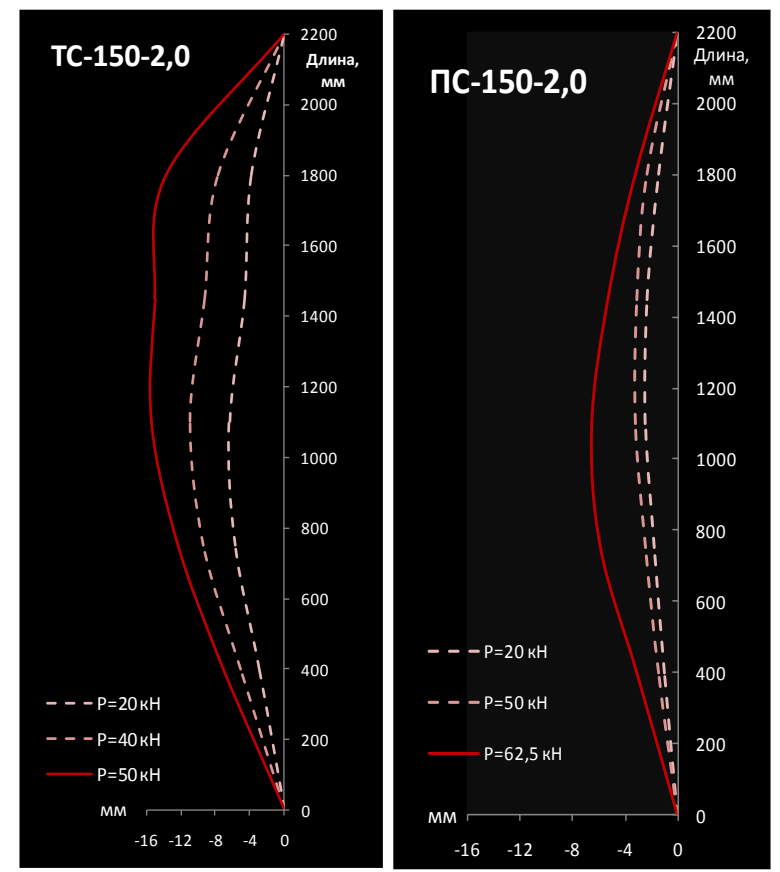

Fig. 9. Comparison study of bending curves for the members with cross-sectional height of $150 \mathrm{~mm}$.

\section{Numerical simulation}

Numerical simulation of stability and inelastic work of thin-walled members made of $\mathrm{C}$-shaped profile with edge bendings is very interesting but rather difficult task of structural mechanics (Vatin, Rybakov 2007). Its solution depends on the reliability of simulation model and is impossible without modern numerical methods. In our work we use PLM Femap 10.1 Nastran for numerical simulation of thin-walled member work. When carrying out calculations we took into consideration the lack of linearity.

Nastran's triangle and fore-cornered fracture finite elements of plate type were used to create finite-element model of the whole member. Fine grid at the places of bending was made manually. Discrete finite element 
model was explored with the help of step-by-step loading and Newton-Raphson's method (Basaglia C. et al. 2013). Elastic module and Poisson's ratio were taken as those for steel $\left(E=2.1 \cdot 10^{5} \mathrm{MPa}, v=0.3\right)$. Diagrams of steel stretching were used. The results are given Fig. 10 .

Simulation of member notches was implemented by means of decreasing of end elements stiffness properties (elastic modulus E). As a result, we got another form of notched C-shaped profile buckling, different from that of solid C-shaped profile.

In future, we are planning to select stiffness of end elements at the zone of notches in order to receive notched $\mathrm{C}$-shaped profile buckling form analogous to the one received during the research.

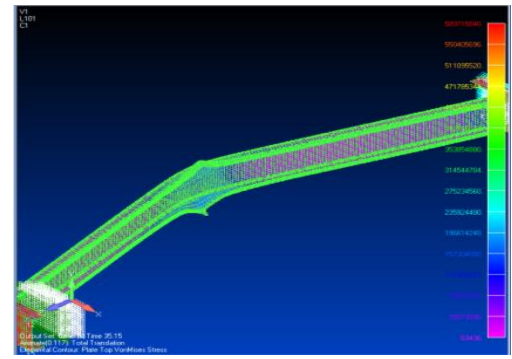

Fig. 10. PLM Femap 10.1 Nastran, global buckling, notched cold-formed C-shaped profile members.

This calculation was carried out to see inelastic bending of the member, and its results were almost completely the same as those of experimental investigations.

\section{Conclusions}

As the result, during our experiment we proved our theoretical estimations.

Global buckling was flexural-torsional, see Fig. 11, real bearing capacity $N=62.2 \mathrm{kN}$. Local buckling of flanges was observed after global buckling.

At the middle loading step $(30 \mathrm{kN})$ we saw distortional cross-section, which amplified torsion.

Having analyzed the received membrane stresses, we understood that coefficient of reduction should be used when notched cold-formed C-shaped profile members are calculated.

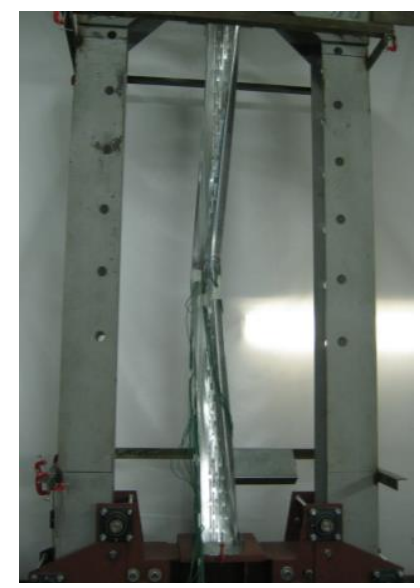

Fig. 11. Member TC-150-2,0, global buckling flexural-torsional.
Analyses of the elastic curves revealed that the profile wall movements are lengthwise and the elastic curve is analogous to the Euler curve. So, the junction of the member and guiding rail with the help of self-tapping screws can be considered pin connection.

Long members have web crippling deformation at the very beginning of the loading stage. Under loads over $35 \mathrm{kN}$ they begin to grow rapidly, the member becomes bent and loses its bearing capacity because of the general stability loss.

Bearing capacity and buckling type of profile is influenced by the profile cross-sectional height $h$ and its thickness, to be more exact, by $h / t$ ratio. Profile with cross-sectional height of $150 \mathrm{~mm}$ experiences less wall displacement than the profile with height of $200 \mathrm{~mm}$.

\section{References}

Ayrumyan, E. L.; Kamenshchikov, N. I., 2006. Frame structures of steel framework from zinc-plated formed profiles for onestorey buildings of various applications. In: World of construction and estate property, 36, pp. 9-11. (in Russian).

Astakhov, I.V., 2006. Spatial stability of structural members from cold-formed profiles. Authors abstract in candidacy for PhD in Technical Sciences. St. Peterburg, 21 p. (in Russian).

Basaglia, C.; Camotim, D.; Silvestre, N., 2012. Post-buckling analysis of thin-walled steel frames using generalised beam theory (GBT). Thin-Walled Structures. 2013. T. 62, pp. 229-242.

Brune, B.; Ungermann, D., 2008. Coupled instabilities of coldformed steel members in minor axis bending. CIMS2008 Fifth International Conference on Coupled Instabilities in Metal Structures, 23-25 June, 2008, Sydney, Australia.

Brune, B.; Ungermann, D., 2008. Direct strength method compared to EN 1993-1-3. EUROSTEEL 2008, 3-5 September, 2008, Graz, Austria.

Cheng, Y.; Schafer, B. W., 2007. Simulation of cold-formed steel beams in local and distortional buckling with applications to the direct strength method. Journal of Construction Steel Research, 63(5), pp.581-590. http://dx.doi.org/10.1016/j.jcsr.2006.07.008

Ghersi, A.; Landolfo, R.; Mazzolani, F. M. Design of Metallic Cold-formed Thin-walled Members. Spon press, London. $174 \mathrm{p}$.

ENV 1993-1-3:2001. Eurocode 3: Design of steel structures Part 1.3: General rules - Supplementary rules for cold formed thin gaugemembers and sheeting. [S. 1.]: BSi, 2001. 128 p. ISBN 0-580-33219-5

Li, Z.; Schafer, B. W., 2010. Application of the finite strip method in cold-formed steel member design. Journal of Constructional Steel Research. 2010. T. 66 (8-9), pp. $971-980$

Perelmuter, A. V.; Slivker, V. I., 2002. Design models of structures and a possibility of their analysis. Kiyv: Stal, 600 p. (in Russian).

Rhodes, J., 2001. Some observations on the post-buckling behaviour of thin plates and thin-walled members. In Proc. of the Third International Conference on Thin-Walled Structures (ICTWS 2001), 5-7 June, 2001, Cracow, Poland.

Rybakov, V. A., 2010. Osnovy stroitelnoy mekhaniki legkikh tonkostennykh konstruksiy. [The fundamentals of light steel thin-walled structural mechanics]. Saint-Petersburg: Izd-vo SPbGPU. 206 p. (in Russian). 
Schafer, B. W.; Li, Z.; Moen, C. D., 2010. Computational modeling of cold-formed steel. Thin-Walled Structures. 2010. T. 48. (10-11), pp. 752-762.

Smaznov, D. N., 2009. Stability of built-up columns subjected to compression, made of profiles from high-strength steel. Civil engineering journal, 3, pp. 42-49. (in Russian)

Tusnin, O. R., 2009. Finite element for numeric analysis of structures of thin-walled open profile bars. Metal Constructions, 15(1), pp. 73-78. (in Ukrainian)

Yurchenko, V. V., 2010. Designing of building framework from thin-walled cold-forming profiles under «SCAD Office» environment. Civil engineering journal, 8, pp.38-46. (in Russian)

Vatin, N. I.; Popova, E. N., 2006. Thermal profile in light gauge steel structures. St. Petersburg: [s. n.], 2006, 63 p. (in Russian)
Vatin, N. I.; Rybakov, V. A., 2007. Analysis of metal structures: the seventh degree of freedom. StroyProfil, 2007, 2(56), pp. 60-53. (in Russian)

Vlasov, V.Z., 1959. Thin-walled elastic bars. Moscow: Fizmatgiz, 1959. 595 p. (in Russian)

Wallace, James A.; Schuster, R.M.; La Boube, R.A., 2001. Testing of bolted cold-formed steel connections in bearing (with and without washers). Final report by Canadian Cold Formed Steel Research Group. Department of Civil Engineering University of Waterloo, Ontario, Canada. March 2001. 33 p.

Zhmarin, E. N., 2012. International association of light-gauge steel construction, Journal «Construction of Unique Buildings and Structures», 2:27-30. (in Russian). 